Article

\title{
Environmental Impact Assessment of Different Warm Mix Asphalts
}

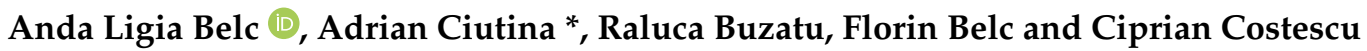

Faculty of Civil Engineering, Politehnica University Timisoara, 300006 Timisoara, Romania; anda.belc@student.upt.ro (A.L.B.); raluca.legian@student.upt.ro (R.B.); florin.belc@upt.ro (F.B.); ciprian.costescu@upt.ro (C.C.)

* Correspondence: adrian.ciutina@upt.ro

Citation: Belc, A.L.; Ciutina, A.; Buzatu, R.; Belc, F.; Costescu, C. Environmental Impact Assessment of Different Warm Mix Asphalts. Sustainability 2021, 13, 11869. https:// doi.org/10.3390/su132111869

Academic Editors: Adrian Burlacu and Giovanni Leonardi

Received: 31 August 2021

Accepted: 25 October 2021

Published: 27 October 2021

Publisher's Note: MDPI stays neutral with regard to jurisdictional claims in published maps and institutional affiliations.

Copyright: (c) 2021 by the authors. Licensee MDPI, Basel, Switzerland. This article is an open access article distributed under the terms and conditions of the Creative Commons Attribution (CC BY) license (https:// creativecommons.org/licenses/by/ $4.0 /)$.

\begin{abstract}
Within the last decade, much attention has been focused on determining viable techniques for producing sustainable asphalt mixtures and minimizing fuel use and greenhouse gas emissions. Thus, warm mix asphalt (WMA) has become a topic of significant interest among road specialists as it offers a potential solution for reducing the environmental impact of the asphalt mixtures due to the decreased temperatures they require for mixing and compaction compared to hot mix asphalt (HMA). The present study is focused on the Life Cycle Assessment (LCA), according to a "Cradle-to-Gate" approach, of hot mix asphalt and warm mix asphalt prepared with locally available materials and different warm mix additives such as organic additives, chemical additive, and synthetic zeolite. For the analysis of the environmental impact of the warm mix asphalts was used a dedicated software for modeling and evaluating the LCA. The WMA prepared with chemical additive or organic additive led to a decrease of the environmental impact, in the production phase, compared to HMA. The study reveals that the raw materials extraction has the greatest impact on the environment in all studied cases, followed by the actual production phase of the asphalt mixture. For WMA produced with additives there was a decrease in the global impact on the environment compared to HMA.
\end{abstract}

Keywords: Life Cycle Assessment (LCA); environmental impact assessment (EIA); hot mix asphalt (HMA); warm mix asphalt (WMA); organic additive; synthetic zeolite; chemical additive; sustainability

\section{Introduction}

Environmental impact assessment of road materials and technologies is a priority in the context of the widespread advocacy of the concept of sustainable development. Regarding the construction of bituminous layers, environmental impact studies may take into account a certain phase of the technological process, usually the asphalt mixture production or the entire life cycle.

Due to the very large amounts of resources used, road construction and maintenance have a major impact on the environment. Consequently, current production technologies need to be properly studied to identify and quantify the environmental impact on the life cycle of the road structure [1-3].

The need to build new road networks and maintain existing ones leads to a global concern about how to reduce the environmental impact from the processes of producing and laying asphalt mixtures. Considerable amounts of greenhouse gases (GHG) and other pollutants are released into the atmosphere during the production of asphalt mixtures and high energy consumption is also used [4]. The intensive consumption of fossil fuels for road production in Europe is responsible for more than $25 \%$ of greenhouse gas (GHG) emissions [5]. The effect of greenhouse gases on the environment and implicitly on climate change are increasingly being analysed worldwide and high effort is being done to develop sustainable technologies to help reduce the ecological footprint of roads [5-7].

The asphalt mixtures industry is constantly researching alternatives to reduce the environmental impact of these construction materials and to conserve natural resources, alongside increasing the efficiency and performance of asphalt mixtures. By introducing 
warm mix asphalt (WMA) technology a substantial decrease in manufacturing temperatures can be achieved and thus the energy used for this purpose, as well as the possibility of introducing a larger amount of reclaimed asphalt pavement (RAP) into the mixture than in the case of usual hot mix asphalt (HMA) [7-9]. The production of asphalt mixtures in a more environmentally friendly manner involves the reduction of production and compaction temperatures, without compromising their physical-mechanical performance.

Life cycle assessment (LCA) is a popular methodology in various fields of research, due to the fact that it analyses the impact on the environment for a product, process, service or activity by recognizing and evaluating the input-output data used by the system and providing the output data in a life cycle perspective $[9,10]$. In the field of roads, the research has been carried out mainly to assess the environmental impact of HMA $[2,5,8,11]$ and HMA containing RAP [12-14]. Due to the growing interest in the production of asphalt mixtures at low temperatures in order to protect the environment, the researchers also addressed the subject of WMA and their comparison with HMA, produced at usual temperatures. Various studies $[7,15,16]$ concluded that the impact of WMA is equal to or slightly lower than that of classic asphalt mixtures, but by introducing the RAP a visible improvement of the impact on the environment can be obtained.

The WMA are prepared and put into operation at significantly lower temperatures than the classic ones. The increase of the workability necessary for the implementation in good conditions is given by special chemical or organic additives or zeolites (either natural or synthetic). D'Angelo et al. [17] show that the application of WMA technologies can lead to the reduction of gas emissions by $10-50 \%$ and the reduction of fuel use by $11-35 \%$.

There are several techniques used to produce WMA such as foaming techniques, organic additive techniques and chemical additive techniques [18]. Several foaming techniques, such as water-based processes $[19,20]$ and water-containing additives [14-16] are mentioned in the specialized literature. The purpose of these techniques is to reduce the viscosity of the binder during the preparation and laying of the asphalt mixture [21]. Adding small quantities of water into hot binders represent another method [22] of reducing the binder viscosity. When water is mixed with the binder, the water transforms into vapour increasing the binder volume and decreasing the binder viscosity for a short period of time. After the mixture cools, the binder will regain the characteristics of a pure bitumen. A uniform blending can be achieved through this technique during the asphalt mixture production. Moreover, it can assure a better coating of the aggregates with the bitumen.

In Europe, based on laboratory and field results, centralizing data over a maximum of 4 years, WMA appear to have equal or even better performance than HMA [23-27]. In the USA, similar performances were certified between the two types of asphalt mixtures after two years of use [28-31].

The advantages of using WMA include: less exposure of workers to harmful gases due to reduced smoke emissions, reduced greenhouse gas emissions and reduced fuel used in the production of asphalt mixtures and improved conditions for laying asphalt mixtures [17,22,23].

Although the mixing and compaction temperatures drop considerably for WMA, this also leads to the need for more accurate dosage control and compliance with the technological process. The current challenge is to demonstrate that the overall performance of these asphalt mixtures is at least identical to that of conventional asphalt mixtures. If during their life cycle, the warm asphalt mixtures do not behave as well as the hot asphalt mixtures then no long-term benefits regarding environmental protection and energy saving can result.

For a more complex analysis of the advantages of WMA compared to HMA, further research has been conducted in Europe, in the United States and China, which has led to the conclusion that this technology for producing asphalt mixtures generates lower greenhouse gas emissions [20,32].

A comparative impact study carried out by Philippot [33], within the GAÏA program, per 1000 tons, between a HMA (BBSG 10) produced at $160^{\circ} \mathrm{C}$ in a gas plant and a WMA 
produced at $110{ }^{\circ} \mathrm{C}$ with $0.3 \%$ chemical additive showed a $24.09 \%$ reduction in energy and liquid fuel consumption and a $27.35 \%$ reduction in greenhouse gas emissions in the case of WMA.

Enormous use of raw materials to produce asphalt mixtures has been recorded in recent decades, e.g., in the USA 350 million tons/year of raw materials, of which 320 million tons of aggregates/year, are used for the production and maintenance of highways [34,35].

In the context of the above mentioned, the aim of the paper is to show the results of a comparative environmental impact assessment of the production stage for a HMA for the surface asphalt layer with a nominal maximum aggregate size of $16 \mathrm{~mm}$ and certain WMAs prepared with the same dosage of materials, but with various additives of organic, chemical and synthetic type in different percentages. Totally, five environmental impact assessment (EIA) analyses were performed.

\section{Analysed Asphalt Mixture Cases}

The analysed asphalt concrete consists of natural crushed aggregates $(54.0 \%$ crushed stone $4 / 16 \mathrm{~mm}$, and $25.6 \%$ crushed sand $0 / 4 \mathrm{~mm}$ ) obtained from diorite, $7.6 \%$ natural sand $(0 / 4 \mathrm{~mm}), 7.6 \%$ filler, and $5.2 \%$ virgin binder with $50 / 70$ penetration grade. All percentages are given by the weight of the asphalt mixture. The following materials were used to prepare the WMA mixtures: an organic additive (a synthetic wax-W), a chemical additive (C), and a synthetic zeolite (Z).

The synthetic zeolite is a sodium aluminium silicate that has been hydro-thermally crystallized. The crystallization is approximately $21 \%$ water by mass which is released from the zeolite structure in the temperature range of $85-180{ }^{\circ} \mathrm{C}$ [36].

The evaluated asphalt mixtures are presented in Table 1.

Table 1. Asphalt mixtures.

\begin{tabular}{ccc}
\hline Asphalt Mixture Type & Additive Type & Additive Percentage \\
\hline HMA & - & - \\
WMA_3\%W & organic additive (wax) & $3.0 \%$ by weight of bitumen \\
WMA_1.5\%W & organic additive (wax) & $1.5 \%$ by weight of bitumen \\
WMA_0.5\%C & chemical additive & $0.5 \%$ by weight of bitumen \\
WMA_0.3\%Z & synthetic zeolite & $0.3 \%$ by weight of asphalt mixture \\
\hline
\end{tabular}

All specimens followed the same mixture design, similar to the one used for the HMA, but with different additives. The percentages of additives and synthetic zeolite were recommended by suppliers. The asphalt mixture dosage and the efficiency of additives used were confirmed by laboratory tests on binders and asphalt mixtures [36,37].

The mixing and compaction temperatures for HMA were 160 and $150{ }^{\circ} \mathrm{C}$. Three WMA combinations of temperatures were selected, noted as follows:

- $\quad \mathrm{T} 1$ : mixing temperature $140{ }^{\circ} \mathrm{C}$, compaction temperature $120^{\circ} \mathrm{C}$;

- $\mathrm{T} 2$ : mixing temperature $120^{\circ} \mathrm{C}$, compaction temperature $120^{\circ} \mathrm{C}$;

- $\quad \mathrm{T} 3$ : mixing temperature $120^{\circ} \mathrm{C}$, compaction temperature $100{ }^{\circ} \mathrm{C}$.

\section{Laboratory Determination, Normative Requirements}

For all the asphalt mixtures, Marshall stability and flow, stiffness modulus, resistance to permanent deformation (creep characteristics), and water sensitivity were determined [36].

Marshall stability helps to determine the optimum binder content and analysing the high-temperature behaviour of the bituminous layer under traffic loads. The flow index represents the deformation reached by the vertical diameter of the specimen at failure [36]. A low Marshall stability and a high Marshall flow shows a low stability at high temperatures for the asphalt mixture. On the other hand, a high Marshall stability and a low Marshall flow can indicate that the bitumen might have a very high consistency or might be burnt during the production of the asphalt mixture. 
Marshall tests were conducted to evaluate the resistance of cylindrical specimens of WMA and HMA to plastic flow. The Romanian standard [38] specifies strict requirements for the minimum and maximum values for Marshall stability as minimum $6.5 \mathrm{kN}$ and maximum $13 \mathrm{kN}$ and flow as minimum $1.5 \mathrm{~mm}$ and maximum $4.0 \mathrm{~mm}$.

Figures 1 and 2 show the values of the Marshall stability and flow for all the asphalt mixtures at the mentioned temperatures (T1-T3). In these figures the horizontal lines represent the reference values obtained for the Marshall stability and Marshall flow for HMA [36].

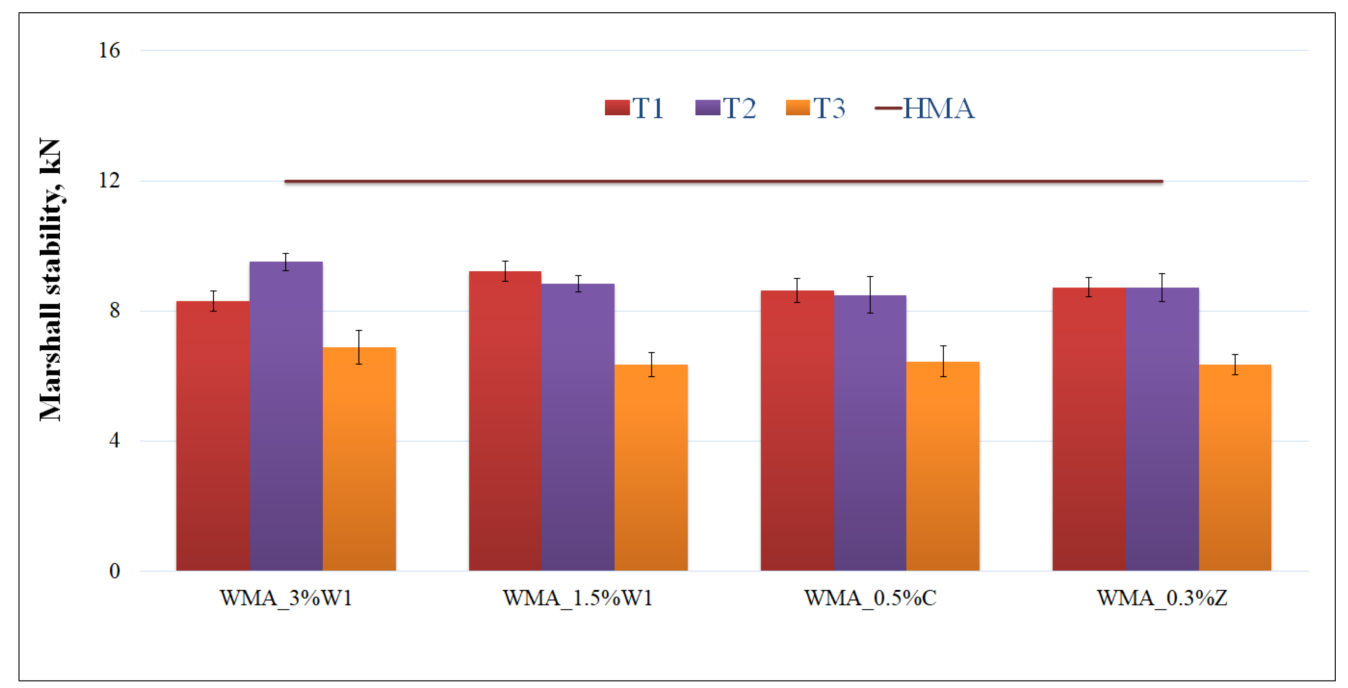

Figure 1. Marshall test results: Marshall stability; the length of the error bar is equal to one standard deviation.

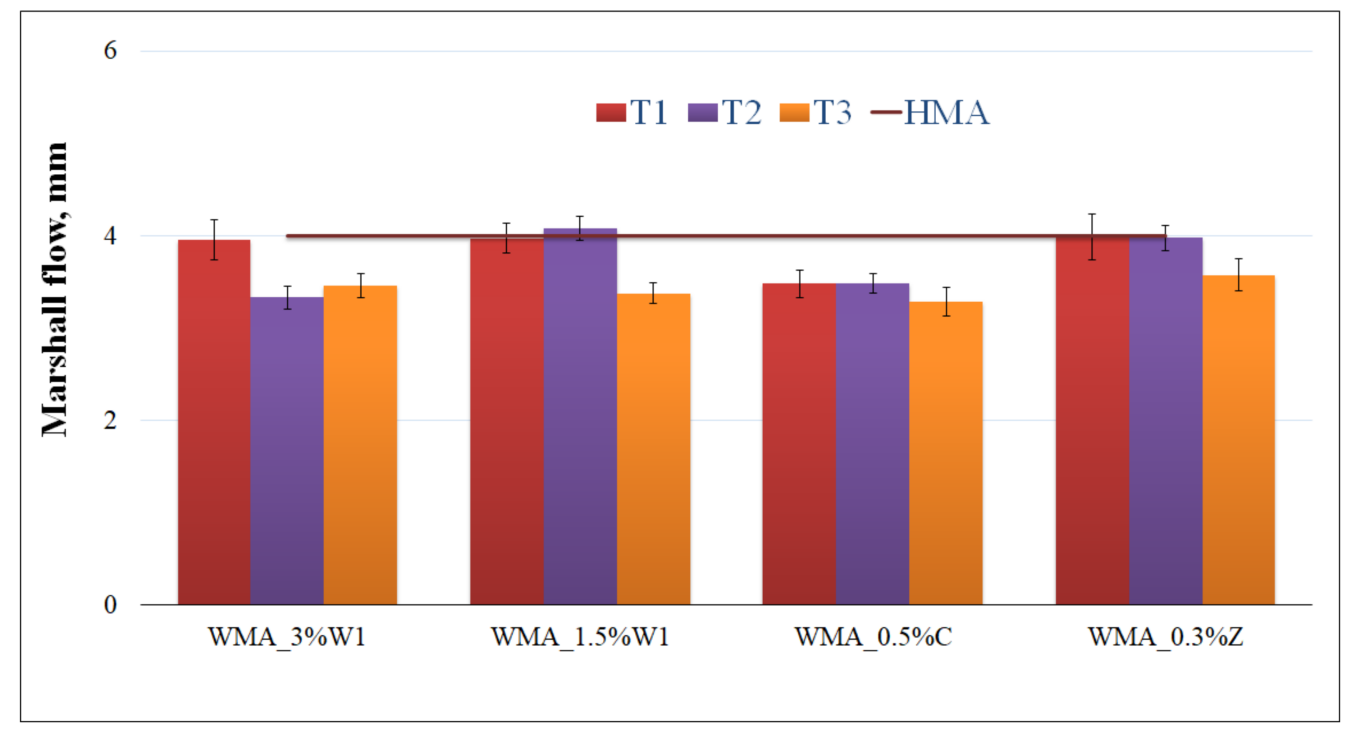

Figure 2. Marshall test results: Marshall flow; the length of the error bar is equal to one standard deviation.

The Marshall stability values for all the WMA mixtures were close for all investigated cases, but lower than the values obtained for HMA. However, it should be noted that WMA values are within the limits specified in the Romanian code and thus they can be safely used [36].

Regarding the other laboratory tests, the WMA presented higher stiffness modulus values than the HMA, the only exception being the WMA with synthetic zeolite. Moreover, the deformation and creep rate values were within the recommended limits [36]. 
All the results showed that the analysed WMA cases could be safely applied to the traffic and climatic conditions of Romania. Among the analysed cases, the WMA prepared with a chemical additive has the most similar behaviour to HMA [36].

\section{Functional Unit and Inventory}

\subsection{Functional Unit Definition}

The environmental impact assessment of the analysed WMA was carried out with the GaBi software for all five stages of the LCA of an asphalt mixture as presented in Figure 3.

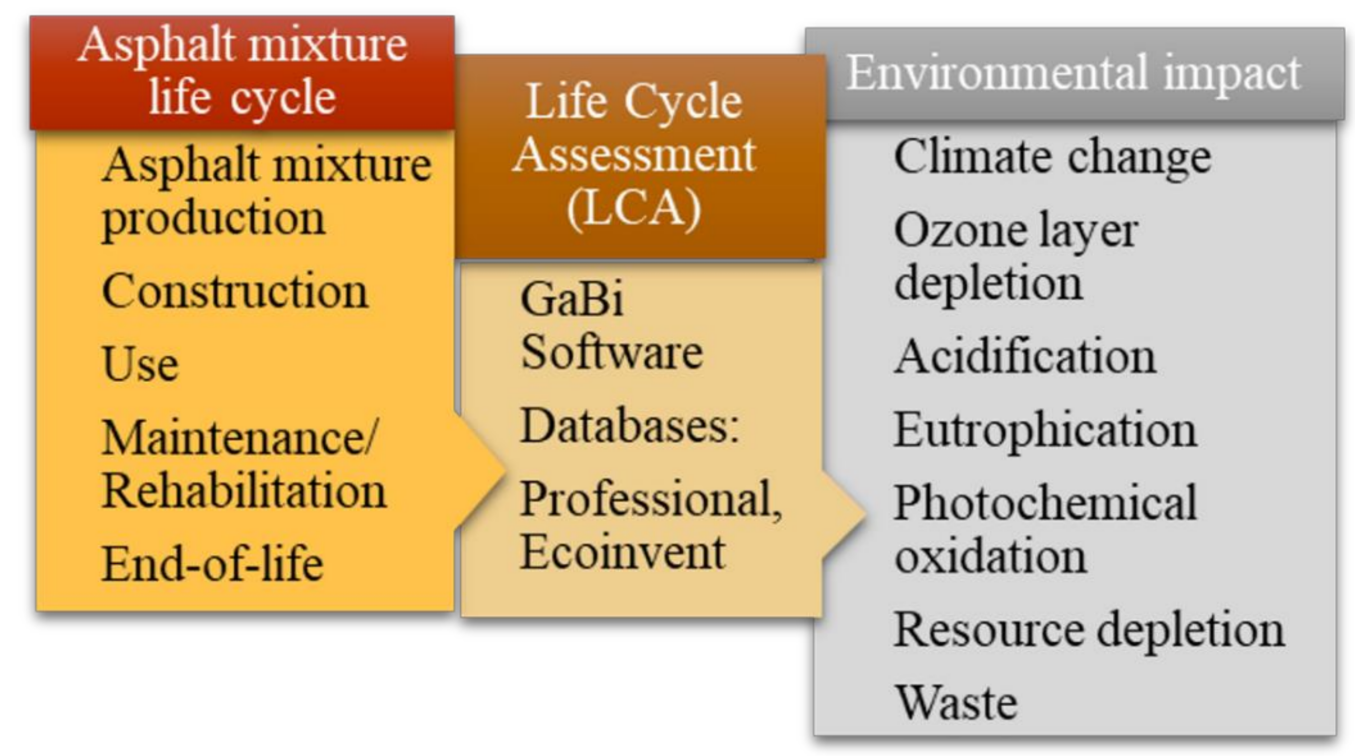

Figure 3. Illustration of the Life Cycle Assessment (LCA) method.

The life cycle of an asphalt mixture usually consists of five main stages, namely: asphalt mixture production, construction, use, maintenance/rehabilitation and end-oflife $[39,40]$. Some standards include the maintenance/rehabilitation phase in the use stage. This research is focused on the cradle-to-gate assessment of the asphalt mixture in order to highlight the impact of the production technology on the environment.

A "functional unit" was defined to perform the environmental impact analysis. This is a reference unit by which the results of the LCA are normalized so that the published data are expressed on a common basis. For a road, the functional unit is defined by the service life, length, type of road and/or width of the road [3,5,7]. In order to compare two different asphalt mixtures, the functional unit must be identical for all analysed cases. Thus, to respect its definition, in this study, the functional unit for asphalt mixtures is defined as the production of one ton $(1 \mathrm{t})$ of asphalt mixture.

In this study, the system model was "Cradle to Gate" with the boundaries shown in Figure 4.

The evaluation of the environmental impact of the WMA was performed using the GaBi software following the rules of EN 15804 + A2 [41] and EN ISO 14044:2006 + A1:2018. The stage of asphalt mixture production is divided in three modules [41] as follows:

A1. Raw materials extraction;

A2. Transport of raw materials to the asphalt mixture plant;

A3. Production of the asphalt mixture at the asphalt mixture plant. 


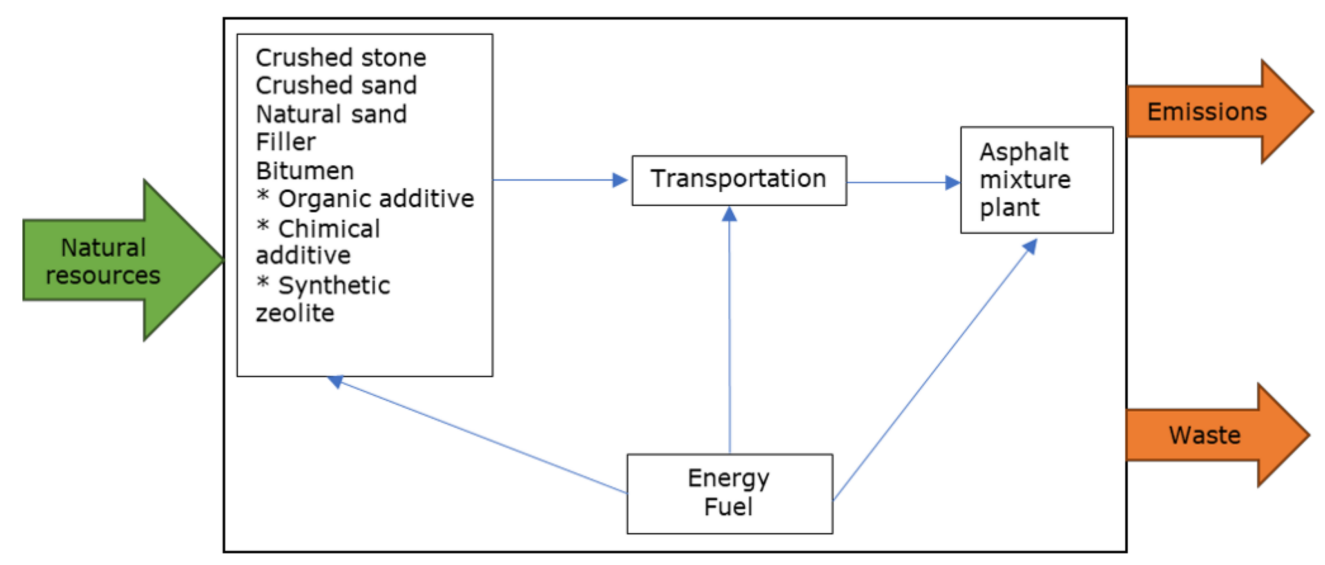

Figure 4. System boundaries considered in the case study.

\subsection{Inventory}

The evaluation of the environmental impact of the HMA and WMA first considers the raw materials extraction module. The next module is the raw materials transportation to the asphalt mixture plant, an action that involves additional consumption of fuel and energy. At the asphalt mixture plant, which is the third module, occurs the actual production of the asphalt mixture. Practically the aggregates are sorted, dried, dusted, weighed and heated, and the bitumen is heated. When using additives, they will be initially mixed in bitumen, and then this mixture will be added to the heated aggregates and filler. The mixing of all these materials completes the asphalt mixture but by using significant energy and fuel. As shown by Santero [40], in the case of asphalt mixtures, the material with the greatest impact on the environment is bitumen.

The flow diagram for the asphalt mixture production stage (Figure 5) was developed. This development includes the three modules and facilitates the identification of the module with the highest environmental impact.

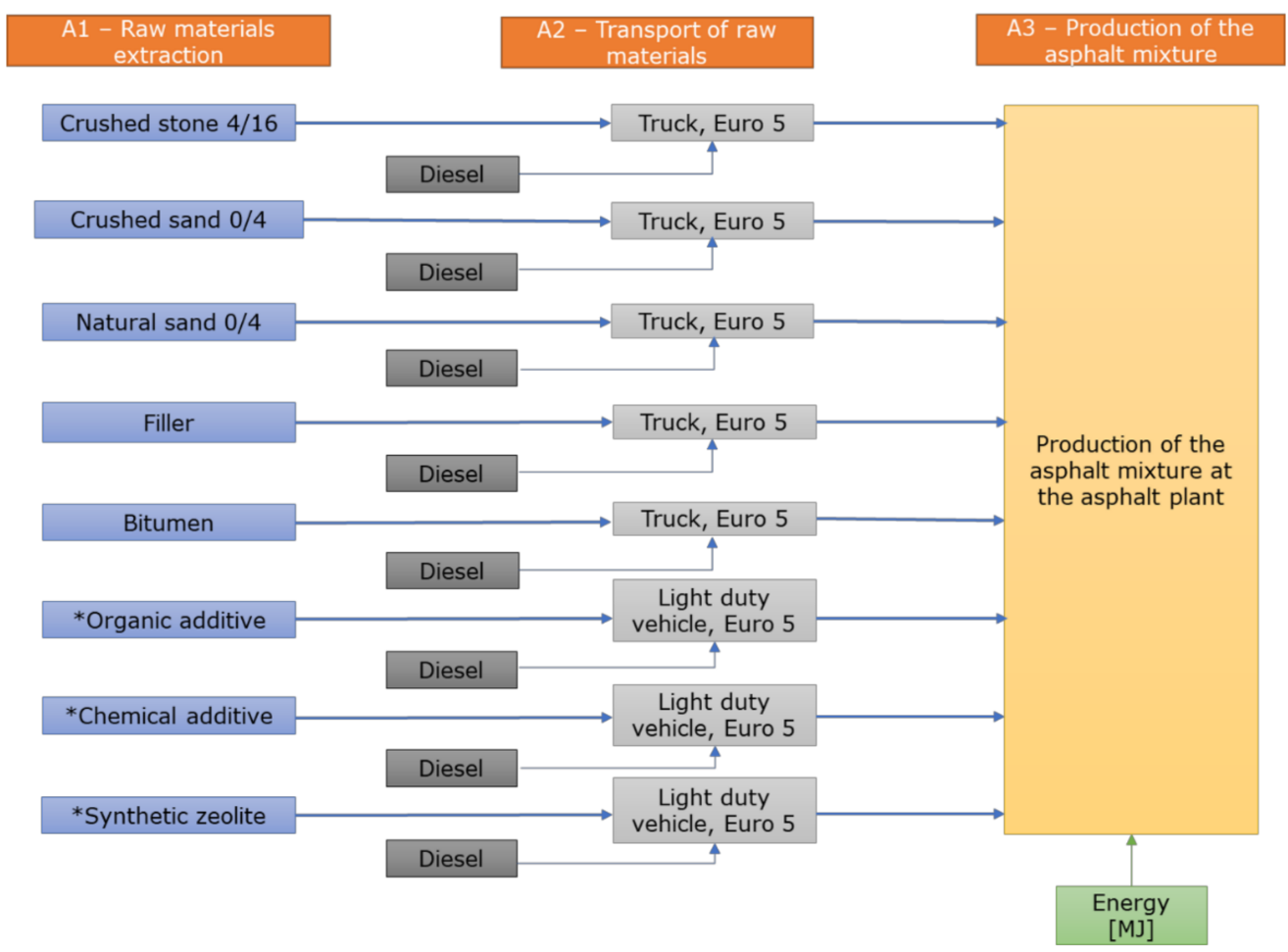

Figure 5. Flow diagram of the asphalt mixtures production process. 
Figure 5 shows the flow diagram describing the manufacturing module applicable for both HMA and WMA. In the case of production of an asphalt mixture at low temperatures, one of the additives will be integrated, corresponding to the chosen technology. In the case of HMA, no additives will be considered, the related materials being only the aggregates, filler, and bitumen. A summary of the data considered is presented in Table 2.

Table 2. Datasets considered for EIA.

\begin{tabular}{|c|c|c|}
\hline Process & Database & Process Dataset Name \\
\hline Crushed stone $4 / 16$ & Professional & $\begin{array}{c}\text { Crushed stone grain 2-15 mm (dried) (EN15804 A1-A3), } \\
\text { EU-28 }\end{array}$ \\
\hline Crushed sand $0 / 4$ & Professional & Crushed sand grain 0-2 mm (EN15804 A1-A3), EU-28 \\
\hline Natural sand $0 / 4$ & Professional & Sand (grain size 0/2) (EN15804 A1-A3), EU-28 \\
\hline Filler & Professional & $\begin{array}{l}\text { Limestone, crushed stone fines (Grain size 0/2) } \\
\text { (EN15804 A1-A3), EU-28 }\end{array}$ \\
\hline Bitumen $50 / 70$ & Professional & $\begin{array}{l}\text { Bitumen at refinery; from crude oil; production mix, at } \\
\text { refinery, EU-28 }\end{array}$ \\
\hline Organic additive & Professional & Wax / Paraffins at refinery, EU-28 \\
\hline Chemical additive & Ecoinvent & $\begin{array}{l}\text { non-ionic surfactant production, fatty acid derivate, } \\
\text { GLO }\end{array}$ \\
\hline Synthetic zeolite & Ecoinvent & zeolite production, powder, RER \\
\hline
\end{tabular}

The transport distances for each of the raw materials were weighed as shown in Table 3, considering the transportation distances representative for the production of the asphalt mixture in the western region of Romania, city of Timisoara.

Table 3. Transport distances.

\begin{tabular}{cc}
\hline Raw Material & Transport Distance, $[\mathbf{k m}]$ \\
\hline Crushed stone 4/16 & 90 \\
Crushed sand 0/4 & 90 \\
Natural sand 0/4 & 90 \\
Filler & 80 \\
Bitumen 50/70 & 220 \\
Organic additive & 75 \\
Chemical additive & 100 \\
Synthetic zeolite & 100 \\
\hline
\end{tabular}

To produce one tonne of HMA a general value of the energy used of $340 \mathrm{MJ}$ was considered according to similar research made by Zaumanis et al. [15]. Regarding the energy consumed for the production of WMA, the literature mentions a reduction of $10-30 \%$ compared to the HMA [3,15,42]. Thus, in this study it was considered a reduced value with $20 \%$ compared to the value considered for the HMA, i.e., $270 \mathrm{MJ}$ for all technologies for obtaining WMA.

In the case of WMA, additional energy was added for the production of chemical, organic additive or synthetic zeolite. As boundary conditions, it was considered that the necessary equipment for the addition of additives or synthetic zeolite is available at the asphalt mixture plant. This calculation principle was considered for the technologies mentioned in this study. However, it is worth mentioning that direct foaming technologies require additional equipment installed in the asphalt mixing plant.

\section{Environmental Impact Assessment}

EIA results were classified and characterized by using characterization factors defined in EN 15804 + A2 [41] for the following impact categories: 
- Environmental impact indicators: climate change, ozone depletion, acidification, eutrophication, photochemical ozone formation, resource use mineral and metals, fossils, water use;

- Resource use indicators: use of renewable primary energy, total use of renewable primary energy resources, use of non-renewable primary energy, total use of nonrenewable primary energy resources, use of net fresh water;

- Output flows and waste categories: hazardous waste disposed, non-hazardous waste disposed, radioactive waste disposed.

The units of measurement do not represent the chemical composition of the pollution itself but represent the amount of a representative standard normalization factor for each type of pollution [43].

Five different asphalt mixtures were evaluated to determine the environmental impact. As a first result, it was observed that the raw materials extraction caused most of the impact. This result was predictable, as the environmental impact of the raw materials extraction module includes also the impact resulted from fuel consumption of vehicles used for the extraction and processing of asphalt raw materials. In this module there are recorded significant consumption of diesel, electricity and gas by employed vehicles.

\subsection{Environmental Impact Indicators}

Figure 6 shows the results for the climate change potential by type of asphalt mixture, in kilograms of equivalent carbon dioxide. Climate change acts as a useful parameter to assess the future impact of emissions on the atmosphere [43]. The main factors contributing to $\mathrm{CO}_{2}$ emissions are (in descending order of importance): raw materials extraction, production of the asphalt mixture and transport of raw materials.

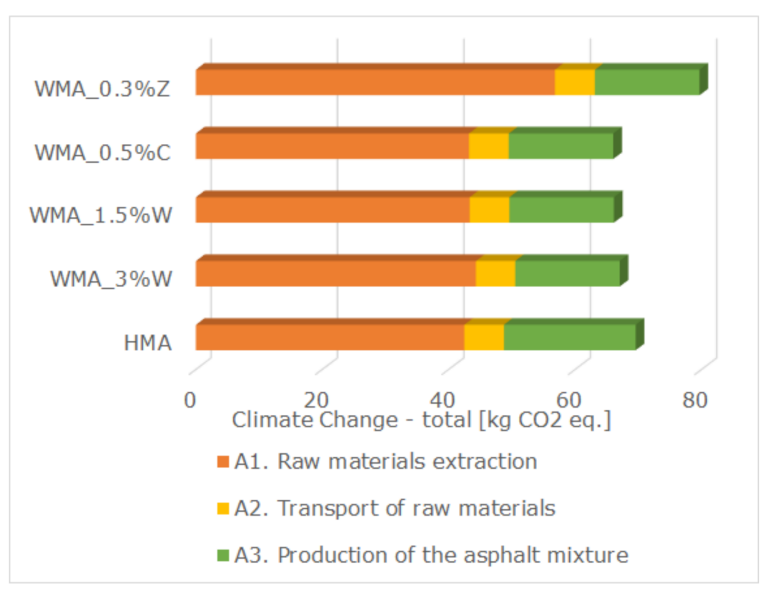

Figure 6. EIA results on climate change impact category.

All the three WMA cases lead to a lower climate change potential than the HMA, while the WMA with synthetic zeolite leads to a higher climate change potential than the HMA, mainly by cause of the impact recorded from the raw materials extraction. Thus, the stage of producing mixtures at lower temperatures has a 10-15\% reduced impact compared to HMA due to the use of a lower amount of energy in this process. This is by reason of the reduction in the manufacturing temperature, which is about $160{ }^{\circ} \mathrm{C}$ for HMA and $120^{\circ} \mathrm{C}$ for WMA. Practically, the $40{ }^{\circ} \mathrm{C}$ temperature reduction has led to environmental impact savings.

Warm asphalt mixtures produced with organic and chemical additive respectively, have a similar environmental impact while the asphalt mixture produced with chemical additive having slightly better performance. According to Figure 6, there is an increase in the environmental impact when using synthetic zeolite, mainly due to the process of obtaining materials. The output results show that the impact of the WMA was greater than the impact of HMA, primarily due to the raw materials extraction module, although the 
only notable difference is in the case of synthetic zeolite. This is due to the differences in composition between the HMA and the WMA. The production of synthetic zeolites uses important quantities of energy and resources, thus the impact of zeolites grows significantly. The increase in WMA impact due to the addition of synthetic zeolite offset the decrease in impact resulting from the reduction in manufacturing temperature leading to a total environmental impact of the WMA with zeolite higher than the impact of the original HMA. In contrast, in the case of the chemical additive and the organic additive, the increase in the environmental impact in the raw materials extraction phase does not lead to an increase in the total environmental impact of the asphalt mixture, as this increase is almost negligible.

The ozone depletion potential is usually affected by energy-consuming processes, such as the procurement of aggregates, the production of bitumen and the manufacture of asphalt mixtures [5]. The values for the ozone depletion are extremely low in all cases assessed over the entire stage of production of asphalt mixtures, consisting of the three modules A1-A3 mentioned above. A minimal increase can be seen again when using synthetic zeolite, as shown in Figure 7a.

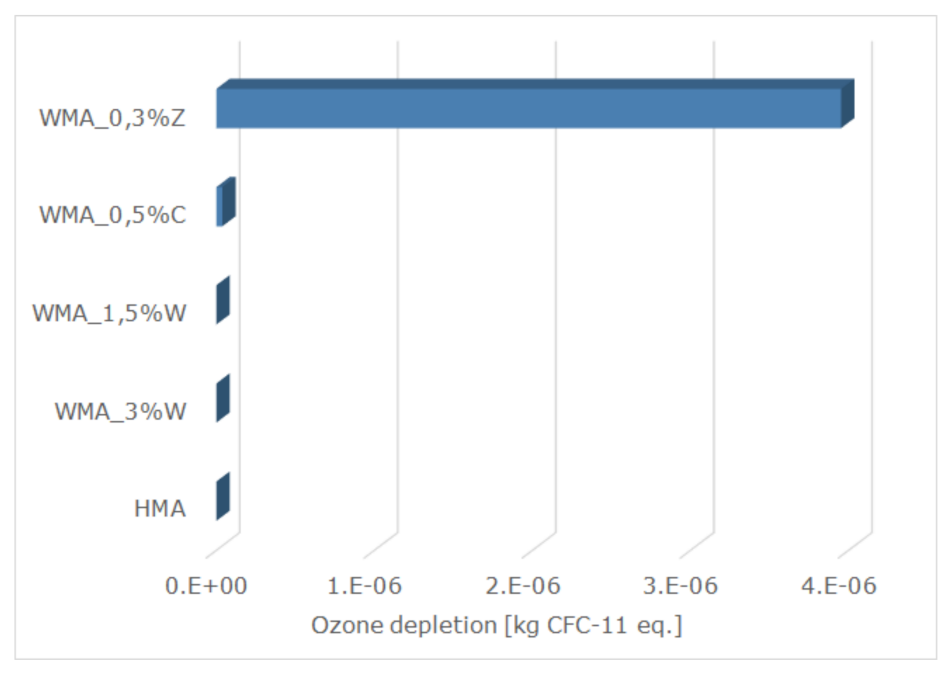

(a)

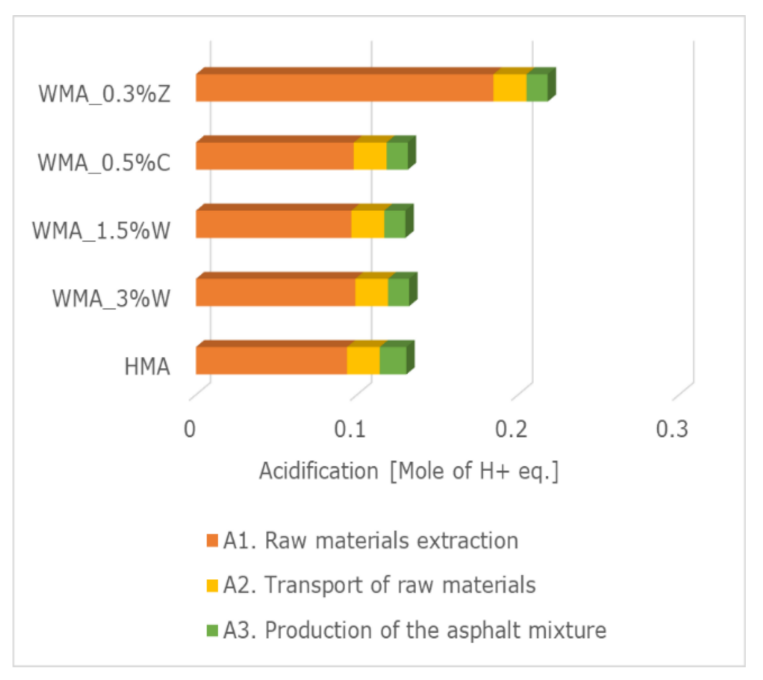

(b)

Figure 7. EIA results on: (a) ozone depletion; (b) acidification.

Figure $7 \mathrm{~b}$ shows the acidification potential of each asphalt mixture studied. Acidification results from carbon dioxide released into the atmosphere which absorbed into ocean waters forms carbonic acid and lowers the $\mathrm{pH}$ of ocean waters [44]. It is noted that in the case of acidification the values are very close between the HMA and the asphalt mixtures prepared at low temperatures. Again, the highest impact has the process of raw materials extraction in all evaluated cases, and the WMA prepared with synthetic zeolite has a greater impact than the HMA.

The trend of results for the acidification potential follow those obtained on the climate change potential. The mixture prepared with the chemical additive has the smallest impact, although all the values are similar.

Figure 8 shows the eutrophication potential of freshwater, marine and terrestrial eutrophication generated by each asphalt mixture. Eutrophication is the process by which nutrients accumulate in an environment or habitat, terrestrial or aquatic. Nutrients are mainly nitrogen exhibited mainly from agricultural nitrates and wastewater and, secondly, from car pollution and phosphorus (mainly from agricultural phosphates and wastewater). Sun or water temperature, which increases with climate change, may exacerbate eutrophication [45]. 


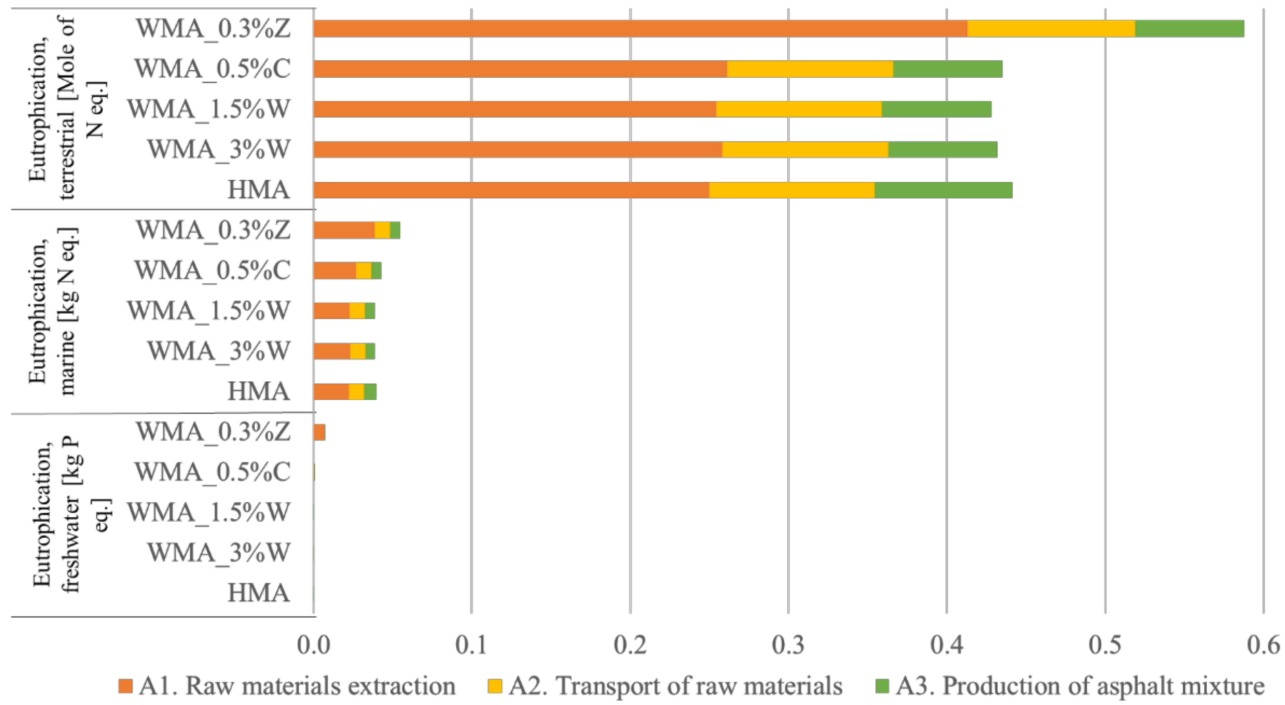

Figure 8. EIA results on eutrophication.

The results indicate that the production phase of the asphalt mixture does not influence the eutrophication of freshwater, it has a low impact on marine eutrophication, and the greatest influence of it occurs on the potential for terrestrial eutrophication. All asphalt mixtures have a similar behaviour, noting, as in other cases, an increase in the impact when using synthetic zeolite, or a slight reduction with the use of chemical additive or organic additive. Nor from the point of view of this category of environmental impact are there any notable differences between the asphalt mixtures analysed.

The photochemical ozone formation is largely attributed to volatile organic compounds (VOC) which are emitted mainly during bitumen production, by burning diesel and the asphalt mixture plant when the bitumen is heated [5]. Figure 9 shows the photochemical ozone formation potential.

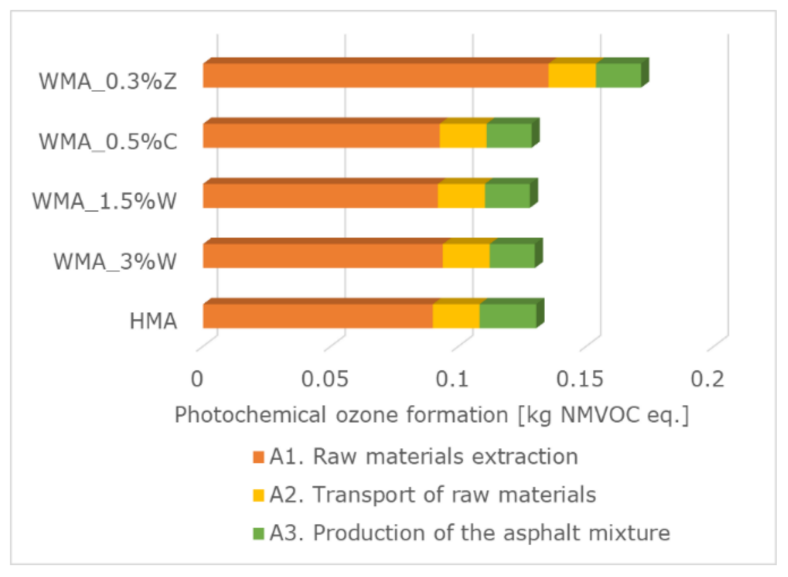

Figure 9. EIA results on photochemical ozone formation.

The difference between the indices of photochemical ozone formation between the two solutions was about $1 \%$ in favour of the WMA with organic and chemical additive respectively, compared to the HMA. An increase of about $30 \%$ in the photochemical ozone formation is noticeable in the case of the mixture with synthetic zeolite compared to the classic asphalt mixture.

Climate change and resource use are among the most studied environmental impact categories in the scientific literature on asphalt mixtures [7]. Figure 10 shows the use of mineral, metal and fossil resources for the five types of asphalt mixtures evaluated. 


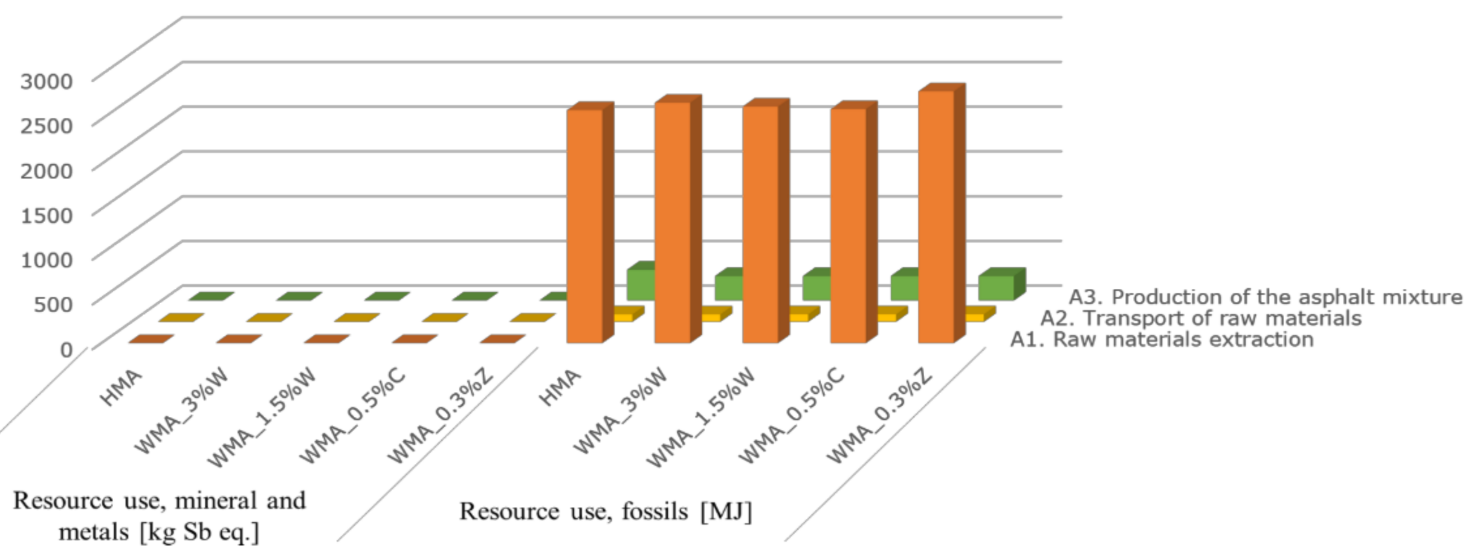

Figure 10. EIA results on resource use, mineral, metals and fossils.

The results show almost zero impact of these asphalt mixtures in terms of consumption of mineral resources and metals. In the case of fossil resources, the highest use is registered in the process of raw materials extraction in all the analysed cases. The WMA with synthetic zeolite and organic additive in a percentage of $3 \%$ by weight of bitumen register slightly higher values than the HMA, while WMA with chemical additive, and with organic additive in a percentage of $1.5 \%$ by weight of bitumen lead to a slightly lower use of fossil resources. The values are extremely close in the five cases, without noticeable differences between HMA and WMA cases.

The water consumption in the production phase of the asphalt mixture is represented graphically in Figure 11.

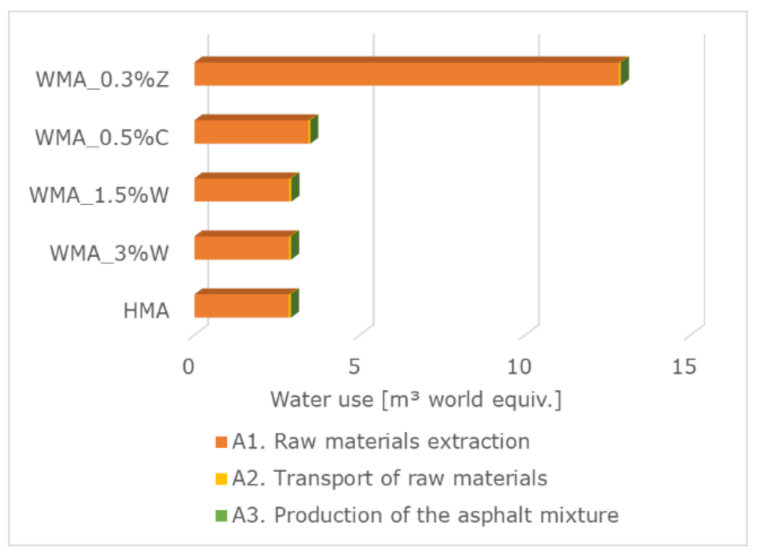

Figure 11. EIA results on water use.

This shows that the process of procuring the component materials leads to the highest water consumption in the phase of asphalt mixture production. In this phase, the actual production of the asphalt mixture at the asphalt mixture plant uses the least amount of water. However, a much higher water usage results in the case of WMA with synthetic zeolite for the manufacture of the asphalt mixture WMA_0.3Z. For the other four types of asphalt mixtures similar values of water use result in the production phase.

\subsection{Resource Use and Waste Categories}

Tables 4 and 5 show the values obtained for resource use indicators, output flows and waste categories. These indicators are presented as total values summing up the values for modules A1, A2 and A3 within the phase of asphalt mixture production. 
Table 4. Resource use indicators.

\begin{tabular}{cccccc}
\hline & \multicolumn{3}{c}{ Asphalt Mixture Production } \\
\cline { 2 - 6 } Resource Use Indicators & HMA & WMA_3\%W & WMA_1.5\%W & WMA_0.5\%C & WMA_0.3\%Z \\
\cline { 2 - 6 } & $\begin{array}{c}\text { Total } \\
\text { A1 + A2 + A3 }\end{array}$ & $\begin{array}{c}\text { Total } \\
\text { A1 + A2 + A3 }\end{array}$ & $\begin{array}{c}\text { Total } \\
\text { A1 + A2 + A3 }\end{array}$ & $\begin{array}{c}\text { Total A1 + A2 + A3 } \\
\text { A1 + A2 + A3 }\end{array}$ & Total \\
\hline $\begin{array}{c}\text { Use of renewable primary } \\
\text { energy (PERE) [MJ] }\end{array}$ & 41.65 & 41.33 & 42.09 & 48.17 & 58.08 \\
\hline $\begin{array}{c}\text { Total use of renewable primary } \\
\text { energy resources (PERT) [MJ] }\end{array}$ & 41.65 & 41.33 & 42.09 & 2973.89 & 317.08 \\
\hline $\begin{array}{c}\text { Use of non-renewable primary } \\
\text { energy (PENRE) [MJ] }\end{array}$ & 3033.20 & 3044.38 & 3002.60 & 2974.76 & 3173.09 \\
\hline $\begin{array}{c}\text { Total use of non-renewable } \\
\text { primary energy resources } \\
\text { (PENRT) [MJ] }\end{array}$ & 3033.20 & 3044.38 & 3002.60 & 0.108 \\
\hline Use of net fresh water (FW) [m3] & 0.095 & 0.094 & 0.095 & 0.327 \\
\hline
\end{tabular}

Table 5. Output flows and waste categories.

\begin{tabular}{cccccc}
\hline \multirow{2}{*}{$\begin{array}{c}\text { Output Flows and Waste } \\
\text { Categories }\end{array}$} & HMA & WMA_3\%W & WMA_1.5\%W & WMA_0.5\%C & WMA_0.3\%Z \\
\cline { 2 - 6 } & $\begin{array}{c}\text { Total } \\
\text { A1 + A2 + A3 }\end{array}$ & $\begin{array}{c}\text { Total } \\
\text { A1 + A2 + A3 }\end{array}$ & $\begin{array}{c}\text { Total } \\
\text { A1 + A2 + A3 }\end{array}$ & $\begin{array}{c}\text { Total A1 + A2 + A3 } \\
\text { A1 + A2 + A3 }\end{array}$ & $1.1 \times 10^{-7}$ \\
\hline $\begin{array}{c}\text { Hazardous waste disposed } \\
\text { (HWD) [kg] }\end{array}$ & $1.1 \times 10^{-7}$ & $1.1 \times 10^{-7}$ & $1.1 \times 10^{-7}$ & $1.1 \times 10^{-7}$ \\
\hline $\begin{array}{c}\text { Non-hazardous waste } \\
\text { disposed (NHWD) [kg] }\end{array}$ & 1.994 & 2.965 & 1.984 & 1.981 & 1.976 \\
\hline $\begin{array}{c}\text { Radioactive waste disposed } \\
\text { (RWD) [kg] }\end{array}$ & 0.011 & 0.011 & 0.011 & 0.011 & 0.011 \\
\hline
\end{tabular}

As it could be noticed from Tables 4 and 5, the values for the environmental impact indicators are very similar, without any noticeable differences. The global values indicate a certain increase in the impact on the environment compared to the HMA when using synthetic zeolite and a slight reduction in the case of using the organic and chemical additives.

\section{Conclusions}

In order to highlight the influence on the environmental impact of the technical solutions that allow the production and implementation of asphalt mixtures at lower temperatures, EIA analyses were performed for five types of asphalt mixtures. A usual asphalt mixture (HMA) was considered to be produced and implemented according to the classical technology, and for the other four the strategy of reducing the temperatures by $40{ }^{\circ} \mathrm{C}$ was adopted by using specific additives in WMA mixtures.

The EIA analyses were performed according to the European LCA norms [41] considering the production phase by the raw materials extraction, their transport to the factory and actual production at the asphalt mixture plant.

The EIA results show that the raw materials extraction process has the greatest impact on the environment in all five cases, followed by the actual production process of the asphalt mixture and the transportation of the materials.

Comparing HMA and WMA, it was observed that the overall impact of WMA is generally smaller than the global impact of HMA with 10-15\%. The WMA with the lowest impact is the one produced with a chemical additive. However, in the case of the WMA with synthetic zeolite, an increase in the environmental impact was noticed for all the studied categories.

Regarding the actual production process of the asphalt mixture, the impact of WMA was about $20 \%$ lower than the impact of HMA, due to the reduction of the manufacturing temperature. The reduction of the impact is mainly in behalf of the reduction of the manufacturing temperature which implicitly leads to the reduction of the energy consumed 
for heating the component materials. However, the impact of the raw materials extraction process was slightly higher in the WMA case when using additives: about $4 \%$ in the case of the organic additive and about $2 \%$ in the case of the chemical additive. For synthetic zeolite there is an increase of about $30 \%$ in the raw materials extraction process. Thus, for this case, the benefits of reducing the manufacturing temperature of WMA, inherently with the reduction of energy consumption at this stage, are partially nullified due to the impact on the environment caused by the production and transport of the used additive.

Considering the whole technological process and the impact of the additives used, the advantages offered by the decrease of the production temperature are diminished. However, there are additional benefits that should not be overlooked. One of these refers to the working conditions in the factory or at the site of the asphalt mixture, giving them the opportunity to work in the vicinity of less hazardous (hot) materials, to inhale less smoke and gas and wear lighter protective equipment.

Author Contributions: Conceptualization, A.L.B., A.C., R.B., F.B. and C.C.; methodology, A.L.B., A.C. and R.B.; software, R.B.; validation, A.C., F.B. and C.C.; investigation, A.L.B., A.C. and R.B.; writing-original draft preparation, A.L.B., F.B. and C.C.; writing-review and editing, A.C. and R.B. All authors have read and agreed to the published version of the manuscript.

Funding: This research received no external funding.

Institutional Review Board Statement: Not applicable.

Informed Consent Statement: Not applicable.

Data Availability Statement: Data sharing is not applicable to this article.

Conflicts of Interest: The authors declare no conflict of interest.

\section{References}

1. Santos, J.; Bressi, S.; Cerezo, V.; Lo Presti, D.; Dauvergne, M. Life Cycle Assessment of Low Temperature Asphalt Mixtures for Road Pavement Surfaces: A Comparative Analysis. Resour. Conserv. Recycl. 2018, 138, 283-297. [CrossRef]

2. Sollazzo, G.; Longo, S.; Cellura, M.; Celauro, C. Impact Analysis Using Life Cycle Assessment of Asphalt Production from Primary Data. Sustainability 2020, 12, 10171. [CrossRef]

3. Ma, H.; Zhang, Z.; Zhao, X.; Wu, S. A Comparative Life Cycle Assessment (LCA) of Warm Mix Asphalt (WMA) and Hot Mix Asphalt (HMA) Pavement: A Case Study in China. Adv. Civ. Eng. 2019, 2019, 9391857. [CrossRef]

4. Thives, L.P.; Ghisi, E. Asphalt Mixtures Emission and Energy Consumption: A Review. Renew. Sustain. Energy Rev. 2017, 72, 473-484. [CrossRef]

5. Schlegel, T.; Puiatti, D.; Ritter, H.-J.; Lesueur, D.; Denayer, C.; Shtiza, A. The Limits of Partial Life Cycle Assessment Studies in Road Construction Practices: A Case Study on the Use of Hydrated Lime in Hot Mix Asphalt. Transp. Res. Part D Transp. Environ. 2016, 48, 141-160. [CrossRef]

6. Rodríguez-Alloza, A.M.; Malik, A.; Lenzen, M.; Gallego, J. Hybrid Input-Output Life Cycle Assessment of Warm Mix Asphalt Mixtures. J. Clean. Prod. 2015, 90, 171-182. [CrossRef]

7. Vidal, R.; Moliner, E.; Martínez, G.; Rubio, M.C. Life Cycle Assessment of Hot Mix Asphalt and Zeolite-Based Warm Mix Asphalt with Reclaimed Asphalt Pavement. Resour. Conserv. Recycl. 2013, 74, 101-114. [CrossRef]

8. Barandica, J.M.; Fernández-Sánchez, G.; Berzosa, Á.; Delgado, J.A.; Acosta, F.J. Applying Life Cycle Thinking to Reduce Greenhouse Gas Emissions from Road Projects. J. Clean. Prod. 2013, 57, 79-91. [CrossRef]

9. Giani, M.I.; Dotelli, G.; Brandini, N.; Zampori, L. Comparative Life Cycle Assessment of Asphalt Pavements Using Reclaimed Asphalt, Warm Mix Technology and Cold in-Place Recycling. Resour. Conserv. Recycl. 2015, 104, 224-238. [CrossRef]

10. Baumann, H.; Tillman, A.-M. The Hitch Hiker's Guide to LCA; Studentlitteratur: Lund, Sweden, 2004; ISBN 91-44-02364-2.

11. Osmani, F.; Hettiwatte, M.; Kshirsagar, S.; Senadheera, S.; Zhang, H. Development of an Environmental Life-Cycle Assessment (LCA) Protocol for Flexible Pavements That Integrates Life-Cycle Components to a Proprietary Software. In Pavement Life-Cycle Assessment; University of Illinois at Urbana-Champaign: Urbana-Champaign, IL, USA, 2017.

12. Aurangzeb, Q.; Al-Qadi, I.L.; Ozer, H.; Yang, R. Hybrid Life Cycle Assessment for Asphalt Mixtures with High RAP Content. Resour. Conserv. Recycl. 2014, 83, 77-86. [CrossRef]

13. Vega, A.D.L.; Santos, J.; Martinez-Arguelles, G. Life Cycle Assessment of Hot Mix Asphalt with Recycled Concrete Aggregates for Road Pavements Construction. Int. J. Pavement Eng. 2020, 1-14. [CrossRef]

14. Qiao, Y.; Dave, E.; Parry, T.; Valle, O.; Mi, L.; Ni, G.; Yuan, Z.; Zhu, Y. Life Cycle Costs Analysis of Reclaimed Asphalt Pavement (RAP) Under Future Climate. Sustainability 2019, 11, 5414. [CrossRef] 
15. Zaumanis, M.; Jansen, J.; Haritonovs, V.; Smirnovs, J. Development of Calculation Tool for Assessing the Energy Demand of Warm Mix Asphalt. Procedia Soc. Behav. Sci. 2012, 48, 163-172. [CrossRef]

16. Calabi-Floody, A.; Vidal, G.; Sanchez-Alonso, E.; Mardones-Parra, L. Evaluation of Gas Emissions, Energy Consumption and Production Costs of Warm Mix Asphalt (WMA) Involving Natural Zeolite and Reclaimed Asphalt Pavement (RAP). Sustainability 2020, 12, 6410. [CrossRef]

17. D'Angelo, J.; Cowsert, J.; Newcomb, D.D. Warm-Mix Asphalt: European Practice; Federal Highway Administration: Washington, DC, USA, 2008.

18. European Asphalt Pavement Association (EAPA). The Use of Warm Mix Asphalt. EAPA Position Paper; EAPA: Brussels, Belgium, 2014.

19. Capitão, S.D.; Picado-Santos, L.G.; Martinho, F. Pavement Engineering Materials: Review on the Use of Warm-Mix Asphalt. Constr. Build. Mater. 2012, 36, 1016-1024. [CrossRef]

20. Button, J.; Estakhri, C.; Wimsatt, A. A Synthesis of Warm-Mix Asphalt; Texas Transportation Institute: San Antonio, TX, USA, 2007.

21. Mohd Hasan, M.R.; You, Z.; Yang, X. A Comprehensive Review of Theory, Development, and Implementation of Warm Mix Asphalt Using Foaming Techniques. Constr. Build. Mater. 2017, 152, 115-133. [CrossRef]

22. Kheradmand, B.; Muniandy, R.; Hua, L.T.; Yunus, R.B.; Solouki, A. An Overview of the Emerging Warm Mix Asphalt Technology. Int. J. Pavement Eng. 2014, 15, 79-94. [CrossRef]

23. Rubio, M.C.; Martínez, G.; Baena, L.; Moreno, F. Warm Mix Asphalt: An Overview. J. Clean. Prod. 2012, 24, 76-84. [CrossRef]

24. Vaitkus, A.; Čygas, D.; Laurinavičius, A.; Vorobjovas, V.; Perveneckas, Z. Influence of Warm Mix Asphalt Technology on Asphalt Physical and Mechanical Properties. Constr. Build. Mater. 2016, 112, 800-806. [CrossRef]

25. Vaitkus, A.; Čygas, D.; Laurinavičius, A.; Perveneckas, Z. Analysis and evaluation of possibilities for the use of warm mix asphalt in Lithuania. Balt. J. Road Bridg. Eng. 2009, 4, 80-86. [CrossRef]

26. Raab, C.; Camargo, I.; Partl, M.N. Ageing and Performance of Warm Mix Asphalt Pavements. J. Traffic Transp. Eng. (Engl. Ed.) 2017, 4, 388-394. [CrossRef]

27. Topal, A.; Sengoz, B.; Kok, B.V.; Yilmaz, M.; Aghazadeh Dokandari, P.; Oner, J.; Kaya, D. Evaluation of Mixture Characteristics of Warm Mix Asphalt Involving Natural and Synthetic Zeolite Additives. Constr. Build. Mater. 2014, 57, 38-44. [CrossRef]

28. Hurley, G.; Prowell, B. Evaluation of Sasobit ${ }^{\circledR}$ for Use in Warm-Mix Asphalt. In NCAT Report 05-06; Auburn University: Auburn, AL, USA, 2005.

29. Hurley, G.; Prowell, B.; Reinke, G.; Joskowicz, P.; Davis, R.; Scherocman, J.; Brown, S.; Hongbin, X.; Bonte, D. Evaluation of Potential Processes for Use in Warm Mix Asphalt. J. Assoc. Asph. Paving Technol. 2006, 75, 41-90.

30. Hurley, G.C.; Prowell, B.D. Evaluation of Aspha-Min ${ }^{\circledR}$ Zeolite for Use in Warm Mix Asphalt. In NCAT Report 05-04; Auburn University: Auburn, AL, USA, 2005.

31. Ali, A.; Abbas, A.; Nazzal, M.; Alhasan, A.; Roy, A.; Powers, D. Effect of Temperature Reduction, Foaming Water Content, and Aggregate Moisture Content on Performance of Foamed Warm Mix Asphalt. Constr. Build. Mater. 2013, 48, 1058-1066. [CrossRef]

32. Barthel, W.; Marchand, J.-P.; von Devivere, M. Warm Asphalt Mixes by Adding a Synthetic Zeolite. In Proceedings of the 3rd Eurasphalt and Eurobitume Congress, Vienna, Austria, 12-14 May 2004.

33. Philippot, G. Conséquences Énergétiques Et Environnementales De L'utilisation Des Enrobés Tièdes Lors De La Construction Des Routes. Master's Thesis, École De Technologie Supérieure Université Du Québec, Montreal, QC, Canada, 2010.

34. Santero, N.; Masanet, E.; Horvath, A. Life-Cycle Assessment of Pavements. Part I: Critical Review. Resour. Conserv. Recycl. 2011, 55, 801-809. [CrossRef]

35. Santero, N.; Masanet, E.; Horvath, A. Life-Cycle Assessment of Pavements Part II: Filling the Research Gaps. Resour. Conserv. Recycl. 2011, 55, 810-818. [CrossRef]

36. Belc, A.L.; Coleri, E.; Belc, F.; Costescu, C. Influence of Different Warm Mix Additives on Characteristics of Warm Mix Asphalt. Materials 2021, 14, 3534. [CrossRef]

37. Belc, A.L.; Pop, I.O.; Belc, F.; Costescu, C.; Fakhari Tehrani, F. Influence of Warm Mix Additives on the Low-Temperature Behavior of Bitumen Using the Bending Beam Rheometer (BBR). Constr. Build. Mater. 2020, 273, 121682. [CrossRef]

38. AND 605-2016 Romanian Standard. Normativ Privind Mixturile Asfaltice Executate la Cald. Conditii Tehnice de Proiectare, Preparare si Punere in Opera a Mixturilor Asfaltice (Standard Concerning Hot Mix Asphalts. Technical Conditions for Designing, Preparing and Laying Asphalt Mixtures). 2016. Available online: https://www.mdlpa.ro/userfiles/proiect_lap.pdf (accessed on 10 October 2021).

39. Harvey, J.; Meijer, J.; Ozer, H.; Al-Qadi, I.; Saboori, A.; Kendall, A. Pavement Life Cycle Assessment Framework; Federal Highway Administration: Washington DC, USA, 2016.

40. Santero, N. Life Cycle Assessment of Pavements: A Critical Review of Existing Literature and Research; Lawrence Berkeley National Laboratory: Berkeley, CA, USA, 2010.

41. EN 15804+A2 Sustainability of Construction Works. Environmental Product Declarations. Core Rules for the Product Category of Construction Products 2019. Available online: https:/ / standards.iteh.ai/catalog/standards/cen/c98127b4-8dc2-48a4-9338-3e136 6b16669/en-15804-2012a2-2019 (accessed on 10 October 2021).

42. Rondón-Quintana, H.A.; Hernández-Noguera, J.A.; Reyes-Lizcano, F.A. A Review of Warm Mix Asphalt Technology: Technical, Economical and Environmental Aspects. Ing. E Investig. 2015, 35, 5-18. [CrossRef] 
43. Intergovernmental Panel on Climate Change (IPCC) Climate Change 2013. The Physical Science Basis. Contribution of Working Group I to the Fifth Assessment Report of the Intergovernmental Panel on Climate Change; Cambridge University Press: Cambridge, UK, 2013; ISBN 978-1-107-66182-0.

44. Feely, R.; Doney, S.; Cooley, S. Ocean Acidification: Present Conditions and Future Changes in a High-CO $\mathrm{CW}_{2}$ World. Oceanography 2009, 22, 36-47. [CrossRef]

45. Carpenter, S.R.; Christensen, D.L.; Cole, J.J.; Cottingham, K.L.; He, X.; Hodgson, J.R.; Kitchell, J.F.; Knight, S.E.; Pace, M.L. Biological Control of Eutrophication in Lakes. Environ. Sci. Technol. 1995, 29, 784-786. [CrossRef] 